\title{
ADEQUAÇÕES CURRICULARES: EIS-ME AQUI, NASCI, LOGO EXISTO!
}

Arilza Landeiro Guimarães Dalonso*

\section{* Universidade Luterana do Brasil. Professora da Rede Municipal de Ensino de Jaguariúna.}

\section{RESUMO}

O presente artigo tem como objetivo discutir o papel das adequações curriculares na vida escolar dos alunos que sofrem alguma disfunção que os impede de seguir com o currículo formal. Para tal, nos baseamos na análise das repostas dadas por professores aos questionários que elaboramos, centrado nos educadores do ensino Fundamental que lecionavam em escolas regulares para os alunos com Transtorno do Espectro Autista (TEA). Dessa forma, foi possível perceber a importância da boa formação docente, para que as adaptações curriculares possam auxiliar na construção de uma escola realmente inclusiva e democrática.

Palavras-chave: Adequações curriculares. Inclusão.Aprendizagem.

\begin{abstract}
This article aims to discuss the role of curricular adaptations in the school life of students who suffer some impairment that prevents them from following the formal curriculum. To do this, we rely on the analysis of the responses given by teachers to the questionnaires that we prepared, focused on the elementary school educators who taught in regular schools for students with Autism Spectrum Disorder (ASD). Thus, it was possible to realize the importance of good teacher training, so that the curriculum adaptations can assist in building a truly inclusive and democratic school.
\end{abstract}

Keywords: Curricular adaptations. Inclusion.Learning. 


\section{INTRODUCAO}

Verificamos que a década de 90 foi muito importante para escola inclusiva, principalmente após os advindos da Declaração de Salamanca, da Lei no 9.394/96 e das Diretrizes Nacionais para Educação Especial na Educação Básica que contemplavam os direitos dos alunos com deficiência a receberem uma educação de qualidade junto com todos seus pares coetâneos

Com o passar dos anos, a cultura escolar foi deixando um pouco o paradigma da integração que era quando o aluno atípico apenas tinha o direito de estar junto com todos os outros alunos típicos e mergulhamos no movimento inclusivo com instrumentalização de ferramentas necessárias para oferecer ao educando um verdadeiro processo de ensino e aprendizagem compatível com suas necessidades, diversidade humana e não apenas o direito de frequentar uma escola regular com a presença física do aluno neste meio. O importante é que se fez necessário estruturar para "atender as necessidades de cada cidadão, das maiorias as minorias, dos privilegiados aos marginalizados”. (WERNECK 1998, p.108).

Para projeções escolares inclusivas, o currículo deve ser inclusivo, flexível, aberto, abrangente e democrático. Tal fato nos levou a estudar um pouco mais sobre o assunto e em prol de todas as crianças com TEA ou alguma necessidade educativa, disseminar e contextualizar as informações sobre adequações curriculares aos colegas de profissão que por algum motivo não tiveram acesso a ela.

Ainscow (2016) defende que para a inclusão acontecer é necessário a transformação do sistema educacional com a presença, participação e aquisição de conhecimentos para todos os alunos, em especial para as crianças com alguma deficiência que demandam de alguma alteração e adaptação no sistema de ensino que não o contemplam de forma funcional. 
Por isso, o presente trabalho visa multiplicar informações sobre adequações curriculares, seja do conceito a sua funcionalidade, ressaltando a importância da formação docente no processo de ensino aprendizagem e sugestionando o PEI (plano educacional individualizado) (MASCARO, 2012, PLESTCH, 2009, PLETSCH; GLAT, 2013, entre outros)aos alunos com Transtorno do Espectro Autista (TEA)como prática educativa inclusiva para dar condições de acesso e permanência para estes alunos.

Carvalho(2006) revela que as adaptações curriculares devem ser encaradas como mais um instrumento para propiciar que a aprendizagem de um certo grupo de alunos seja eficiente para flexibilizar o processo de maneira individualizada ou em grupo, reconhecendo as potencialidades de cada aluno, a diversidade e a pluralidade.

Blanco (2004) realiza bons posicionamentos referente a esta diversidade escolar e que trabalhar com a diversidade $\mathrm{e}^{\prime}$ romper com este esquema tadicional que por todo o sempre nos foi imposto um dia de que todos devem fazer as mesmas coisas, da mesma forma, no mesmo tempo, com os mesmos recursos, estratégias e materiais.

Rodrigues (2003) defende que um aluno para estar incluído necessita muito mais do que ir à escola, precisa ter acesso, participar e aprender com condições próprias de aprendizagem e diferenciação curricular. Rodrigues em 2003 confirma dos mesmos ideais que Assmann (2001) que menciona “o aprender se refere ao desenvolvimento de uma rede de experiências pessoais de conhecimento socialmente validável no convívio humano (ASSMANN, 2001, p.192)

Levando em consideração a grande discussão que existe acerca da importância da adaptação curricular para uma verdadeira inclusão de alunos com necessidades educativas diferentes, o interesse por tal tema surgiu durante ações pedagógicas inclusivas, onde percebemos o insucesso das propostas pedagógicas elaboradas para crianças que não acompanhavam a proposta rígida do currículo formal que foi criado para uma escola sem 
alunos com deficiência. Conhecendo o uso das adequações curriculares por meio de formação docente e estudos, e os sucessivos avanços dos alunos com este recurso, pudemos verificar o sucesso destas crianças, só que para isto acontecer, várias nuances devem ser levadas em consideração, em especial, a forma como o currículo é exposto e resinificado pela criança.

Para elaboração deste trabalho, utilizamos a metodologia de pesquisa de Severino(2007, p.125), para pesquisa de campo SAMPIERI, R. H.; COLLADO, C.F.; LUCIO, P.B, 2006 para a verificação bibliográfica, nos beneficiando dos autores (ASSMANN, 2001, CARVALHO, 2006, GONZALEZ, 2002, MCLAREN, 1998, OLIVEIRA, 2008, REGANHAN; MANZINI, 2009, RODRIGUES, 2003, SANCHES; TEODORO, 2006, WERNECK, 1998), entre outros, para conhecimento sobre o assunto estudado.

\section{DO CURRÍCULO ÀS ADEQUAÇÕES CURRICULARES}

Neste primeiro momento seria pertinente conhecer um pouco de currículo e a cultura que o rege, para posteriormente compreender melhor a origem das adequações curriculares e sua funcionalidade em nosso meio.

Pensando em currículo e cultura, Maclaren (1998) reproduz algumas ideias sobre o currículo bem pertinentes quando se considera o ser como totalidade e não apenas um aspecto cognitivo exclusivo.

\footnotetext{
Representa muito mais do que um programa de estudos, um texto em sala de aula ou o vocabulário de um curso. Mais do que isso, ele representa a introdução de uma forma particular de vida; ele serve, em parte, para preparar os estudantes para posições dominantes ou subordinadas na sociedade existente.O currículo favorece certas formas de conhecimento sobre outras e afirma os sonhos, desejos e valores de grupos seletos de estudantes sobre outros grupos, com frequência discriminando certos grupos raciais, de classe ou gênero. (MACLAREN, 1998, p.116)
}

As ideias de MacLarene a dos Parâmetros Curriculares Nacionais (PCNs) se complementam em si mesmo para evidenciar os conceitos de currículo como um todo, porque se pensarmos em currículo apenas para 
competências e resultados, não daremos conta do desenvolvimento do sujeito na sua totalidade e apenas como habilidades intelectuais.

Segundo os Parâmetros Curriculares Nacionais, o currículo foi adotado para orientar os níveis de ensino em suas concepções e ações.

A concepção de currículo inclui, portanto, desde os aspectos
básicos que envolvem os fundamentos filosóficos e
sociopolíticos da educação até os marcos teóricos e
referenciais técnicos e tecnológicos que a concretizam na sala
de aula. Relaciona princípios e operacionalização, teoria e
prática, planejamento e ação. (BRASIL,1998, p.31)

O currículo norteia o que, quando e como ensinar, mas verificando que alguns alunos não conseguem acompanhar este currículo regular por condições cognitivas, físicas e até mesmo psíquicas, foram criadas as adaptações curriculares para promover a aprendizagem de todos, inclusive daqueles que não eram favorecidos pelo currículo formal. Glat(2009) cita o currículo dinâmico, que seria um currículo inclusivo onde não podemos desprezar o fator cultural de cada comunidade escolar e até mesmo do público em demanda, e que a escola se adapta ao aluno e não o aluno que deve se adaptar a escola, porque se for para o aluno se adaptar a escola, não acontecerá a inclusão devido as próprias necessidades de cada educando.

Em meio a uma certa individualidade e até mesmo subjetividade que a educação formal carrega em seu sentido implícito e explícito, devemos considerar as peculiaridades que este processo de ensino-aprendizagem nos oferece seja como resposta de uma ação ou como ferramenta de um processo.

Quando falamos de educação para crianças com alguma deficiência, professores devem estar sensíveis e ter um olhar amplo, generalista e desenvolvimentista, encarando o componente global como algo vital, precisando por muitas vezes fazer um ajuste no currículo, adequar a proposta ou modificar a estrutura como cada execução apresentada ao alunado.

Pode constatar-se que a perspectiva centrada no individuo com necessidades educativas especiais se alarga a todos os 
alunos, o que vai obrigar a um outro olhar sobre o papel da escola na sociedade, exigindo mudanças metodológicas e organizacionais importantes.Não será uma escola que seleciona, mas uma escola que faz a inclusão de todos através das aprendizagens, porque o aluno está na escola para aprender, para ter sucesso, independente das suas dificuldades e diferenças.Aprender a trabalhar com a diferença para que cada um possa viver com a sua diferença é o grande desafio da escola e de seus profissionais e é isso que vai fazer mudar tudo. É preciso mudar o olhar sobre a escola e repensar o papel que a educação pode desempenhar na qualidade de vida do homem.(SANCHES ;TEODORO 2006, p.75-76)

Tendo o aluno como principal ator no processo, este olhar que Sanches e Teodoro alertam ser necessário, revela que todo ser humano é cabível de aprendizagem e que devemos encarar a inclusão como algo real, apesar de esbarrar em vários obstáculos. Isto tudo contribui para um ambiente educacional inclusivo e com respostas educacionais positivas, dando início a efetivação de um direito dado a todos que, ou seja, à uma educação de qualidade independente de qualquer restrição que o sujeito ofereça, seja física, intelectual, visual, auditiva, múltiplas, transtornos globais do desenvolvimento ou altas habilidades.

Vygotsky (1997) já defendia a proposta de atividades direcionadas que evidenciassem o processo e não o produto final como forma de dar uma maior qualidade a vida a estes educandos que necessitam de alguma adaptação no seu curso escolar.

\section{ADAPTAÇÕES CURRICULARES}

As adaptações curriculares devem estar contempladas no Plano Municipal, no Plano de Ensino do professor, no Plano Educacional Individualizado e no Projeto Político Pedagógico focado na organização escolar e acesso aos serviços de apoio. A LDBEN já relata no seu artigo 59inciso I que "os sistemas de ensino assegurarão aos educandos com necessidades especiais: currículos, métodos, técnicas, recursos educativos e organização específica para atender as suas necessidades”(BRASIL, 1996).Tudo isto “currículos, métodos, técnicas, recursos educativos e 
organização específica" nada mais é do que adequações curriculares.

Neste trabalho entendemos adequações e adaptações como sinônimos e podem ser classificadas em ajustes de grande porte ou significativas que deverá ser de incumbência do diretor ou da área político administrativa e as adaptações de pequeno porte também conhecidas como não significativas que são priorizadas e legitimadas pelo professor.

Adequações curriculares são respostas educativas que devem
ser dadas pelo sistema educacional para favorecer todos os
alunos, possibilitando o acesso ao currículo, sua participação
integral e o atendimento as necessidades educacionais
especiais. (OLIVEIRA, 2008, p.140)

Esses ajustes são necessários e considerados como estratégias diferentes das realizadas com alunos típicos que não possuem nenhuma restrição, como forma de prover a aprendizagem e o acesso ao currículo de quem tem alguma necessidade educativa.

Conforme descreve as Diretrizes Curriculares Nacionais para a Educação Especial na Educação Básica as adequações curriculares devem ser realizadas para alguns educandos quando este "não possa beneficiar-se do currículo da base nacional comum, deverá ser proporcionado um currículo funcional para atender as necessidades práticas da vida. " (BRASIL 2001, p.58)

Levando em consideração todo processo que se dá o nome de inclusão, possuindo uma diversidade humana enorme, com diversas tipologias como fator primordial e a troca das diferenças como a questão norteadora da educação inclusiva, existe a necessidade pedagógica de vários ajustes, alterações, modificações e flexibilizações no contexto escolar. (PRIETO, 2009)

\section{ADAPTAÇÕES DE GRANDE PORTE}

As adaptações de grande porte também conhecidas como significativas são assim chamadas porque permitem o ingresso, a participação e a permanência de todos na sociedade, identificando as 
necessidades e implementando ajustes necessários para favorecer a inclusão.

\begin{abstract}
Adaptações Curriculares de Grande Porte, ou seja, daqueles ajustes cuja implementação depende de decisões e de ações técnico-politico-administrativas, que extrapolam a área de ação especifica do professor, e que são da competência formal de órgãos superiores da Administração Educacional Pública. (BRASIL, 2000a, p.10)
\end{abstract}

Cabe as Secretarias Municipais de Educação em conjunto com as unidades escolares, mapear o público que irá precisar das adequações, identificando suas necessidades para cumprir a participação de todos, planejar e implantar as modificações, adotar propostas curriculares flexíveis e reorganizar a estrutura e funcionalidade da escola. Devem-se estabelecer prioridades, categorizando cada modificação em curto, médio e longo prazo para que realmente todas as adequações planejadas sejam realizadas, pois nem tudo se consegue realizar de uma vez só, principalmente por se tratar em alguns momentos de alterações físicas de ambiente.

As adaptações de grande porte são de seis tipologias e foram definidas pelos elementos curriculares a que fazem parte como adaptações de acesso ao currículo, adaptações de objetivos, adaptações de conteúdo, adaptações do método de ensino e da organização didática, adaptações do sistema de avaliação e adaptações de temporalidade. (BRASIL, 2000a)

As adaptações de acesso ao currículo consistem em oferecer condições e reformulações nas estruturas físicas do ambiente para mobilidade ou favorecimento de ambientes para aprendizagem, recursos materiais específicos para comunicação ou desenvolvimento da aprendizagem, adaptação de material já existente, formação continuada para os profissionais envolvidos e garantia de ações para manter a interdisciplinaridade na integração de conteúdos entre disciplinas e transdisciplinariedade, ampliando a abordagem e aplicabilidade dos conteúdos.

Aos alunos neurotipicos que não possuem nenhuma ressalva no desenvolvimento e aprendizagem, estes conseguem cumprir os objetivos 
gerais e padrão oferecido pelo currículo comum. Já os alunos atípicos, vão desenvolver uma dificuldade bem maior para que isso aconteça, por isso se faz necessário a introdução de objetivos específicos que seja de necessidade do aluno que possui alguma restrição, identificando "o que " este aluno precisa aprender e que seja importante para ele em cada disciplina escolar, e que o mais importante, seja funcional para o seu cotidiano de vida, visando autonomia social. Estas são consideradas adaptações de objetivos quando cada um aprenderá o que precisa, da forma que precisa e no tempo que necessita, revelando objetivos significativos para a vida e favorecendo a permanência deste de forma igualitária na escola regular.

As adaptações de conteúdos representam as especificidades dos conteúdos que o aluno necessite, mesmo que para isto alguns conteúdos básicos do currículo regular precisem ser eliminados, lembrando que se um objetivo for retirado do plano de ensino, este conteúdo também será, assim como se algum objetivo for adicionado, este conteúdo também fará parte do processo de ensino aprendizagem. Este aluno precisa ser estimulado pelo professor com um plano educacional individualizado para oportunizar sua aprendizagem.

Considerando que as adaptações do método de ensino e da organização didática são adaptadas para alguns alunos que precisam de métodos diferenciados de aprendizagem devido suas necessidades educativas, podendo ser uma organização espacial diferenciada na sala, números de alunos compatíveis para que o professor consiga realizar um bom trabalho e desenvolvimento de trabalho integrado entre a educação regular/especial de forma cooperativa entre os professores que fazem parte dessas duas esferas. Estas decisões são de competência político administrativa para propiciar uma classe inclusiva com uma convivência saudável e respeitosa.

O campo das avaliações é bem complexo e necessita de adaptações do sistema de avaliação, haja vista que já receberam adaptações nos objetivos e conteúdos 
As adaptações significativas na avaliação estão vinculadas as alterações nos objetivos e os conteúdos, que foram acrescentados no Plano de Ensino ou dele eliminados. Desse modo, influenciam os resultados que levam, ou não, à promoção do aluno e evitam a cobrança de conteúdos e habilidades que possam estar além de suas atuais possibilidades de aprendizagem e aquisição. (BRASIL, 1998, p.40)

A avaliação não pode ser encarada como verificador quantitativo e sim como retomada de conteúdos de forma continua para reformulações de ações pedagógicas, visando a aprendizagem com cobranças reais e possíveis. Outra adaptação de grande porte é a permanência etária das crianças com os parceiros coetâneos por responsabilidade política administrativas.

As adaptações de temporalidade são verificadas quanto ao tempo de permanência de cada aluno em determinada série desde que se respeite a faixa etária da classe com um plano de ensino individualizado.

\section{ADAPTAÇÕES DE PEQUENO PORTE}

São estas as de competência do professor que devem ser realizadas, para promover a aprendizagem dos alunos que possuem alguma restrição ou que aprendem de forma diferenciada por algum fator.

\footnotetext{
São denominadas de Pequeno Porte (Não Significativas) porque sua implementação encontra-se no âmbito de responsabilidade e de ação exclusivos do professor, não exigindo autorização, nem dependendo de ação de qualquer outra instancia superior,nas áreas políticas, administrativa, e/ou técnica. (BRASIL, 2000b, p.8)
}

As adaptações de pequeno porte devem ser realizadas nos objetivos, nos conteúdos, no método de ensino e organização didática, no processo de avaliação e na temporalidade do processo de ensino aprendizagem para beneficiar os diversos alunos que necessitam de um suporte e os professores inclusivos de forma a atendê-los "para onde e como dirigir a ajuda que os alunos necessitam" (GONZALEZ 2002, p.164)

As adaptações de objetivos se trata de o professor adequar os 
objetivos pedagógicos a real condição do aluno, evidenciando as verdadeiras necessidades e potencialidades, compreendendo toda a diversidade oferecida pelo universo disposto e a potente funcionalidade para a vida deste discente, de acordo com uma escala de prioridade que já foi traçada pelo profissional anteriormente. Pode-se acrescentar ou retirar alguns objetivos de um plano de ensino traçado para todos os parceiros coetâneos em detrimento da realidade do processo de aprendizagem destes alunos que necessitam de algum ajuste com prioridades de objetivos para condições de uma participação produtiva com aquisição de novos conhecimentos essenciais para a vida em sociedade com a ajuda de diversos recursos didáticos alternativos.

As adaptações de conteúdos vão estar intimamente ligadas à adaptação de objetivos. A partir de objetivos traçados, caminhamos com os conteúdos necessários para cada caso. Uma unidade temática pode ser priorizada, enfatizada, reformulada ou até mesmo eliminada. É de competência do professor estudar, traçar e estabelecer os conteúdos que serão abordados para cada criança, levando-se em conta sempre a funcionalidade do mesmo na vida que o atendido leva e as condições que ele vive.

Depois de traçados os objetivos e elencados os conteúdos a que irá trabalhar com cada estudante, chega a hora do método, ou seja, como tudo irá acontecer. Este momento é crucial e de elevada importância já que cada aluno tem suas peculiaridades no desenvolvimento sendo necessário conhecer o público para investir e definir como cada um participará do processo e como cada sujeito aprende de forma efetiva e produtiva, considerando que cada um aprende de uma forma diferente. Será necessária uma análise criteriosa, sinalizando ajustes, retrocedendo ou avançando nas ações pedagógicas, ajustando e selecionando o material a ser trabalhado, refletindo sobre o nível de complexidade e oportunizando técnicas diversificadas para se chegar a adaptação do método de ensino e da organização didática.

Avaliar é um processo complexo, mais como todas as etapas do 
processo ensino-aprendizagem receberam seus ajustes, a avaliação também deverá ser favorecida para obtenção de resultados caracterizando a adaptação do processo de avaliação. Segundo Vasconcellos (1995, p. 78) "a avaliação deve atingir todo o processo educacional e social, se quisermos efetivamente superar os problemas".

Podemos considerar que os objetivos, conteúdos, método e avaliação sejam parte de um ciclo sem fim quando visamos a aprendizagem, pois consideramos o que seja pertinente aprender (objetivos), o que aprender(conteúdo) e como aprender(método).

O avaliar seria verificar se todas essas etapas (objetivos, conteúdos e método) aconteceram em conformidade com o processo para atender as necessidades do educando. Caso a resposta seja negativa, a avaliação será um norteador sempre levando em consideração de onde partiu e para onde se quer chegar.

A avaliação educativa é um processo complexo que começa com a formação de objetos e requer a elaboração de meios para obter evidências de resultados para saber em que medida foram os objetos alcançados e formulação de um juízo de valor. (SARUBBI, 1971, p. 34)

A avaliação será um sinalizador para o replanejamento do trabalho do professor e da aprendizagem deste aluno e não um verificador quantitativo, já que o aspecto qualitativo se sobrepõe ao quantitativo.

O último ajuste seria chamado de adaptação na temporalidade do processo de ensino e aprendizagem, relativizando o tempo empregado para aprendizagem de acordo com cada caso, podendo dispensar mais ou menos tempo para cumprir os objetivos previstos no planejamento realizado pelo professor e consolidação dos conteúdos.

\section{FORMAÇÃO DOCENTE}

A formação docente é de extrema importância para se ter acesso as novas informações e ações pedagógicas mais eficientes. A LDBEN no seu artigo 59 no inciso III garante aos alunos com alguma necessidade, 
professores capacitados para o atendimento especializado e para o ensino regular em classes comuns, por isso a importância das capacitações aos professores para se ter um sistema inclusivo eficiente focado na criança que necessita das adaptações na escola regular, com professores trabalhando com a diferença e a diversidade, peculiaridades e singularidades.

\footnotetext{
A formação continuada como processo que ocorre ao longo da carreira e vida, principalmente articulada ao contexto de atuação profissional, num movimento de auto-conhecimento e de conhecimento dos diversos fatores que interferem na docência. Aos poucos o professor vai assumindo posturas e desenvolvendo autonomia em contextos sócio-historicos que naturalmente sofrem constantes transformações e em velocidade que vem aumentando vertiginosamente em função da produção acelerada de conhecimento. (RESENDE; FORTES, 2005, p.1)
}

Resende e Fortes (2005) tem se debruçado sobre os processos de formação docente. Reganhan e Manzini (2009, p.133) comentam em suas pesquisas que mesmo após os professores realizarem alguns ajustes ou adequações para as necessidades dos alunos, muitos dos profissionais da educação necessitariam de "uma base teórica mais sólida na formação desses professores no sentido de explicar suas ações pedagógicas" já que muitos professores realizam modificações sem saber o porquê "Para realizar adaptação é necessário conhecer detalhadamente o desenvolvimento normal (biomecânico, motor e sensorial)". Além de conhecer o desenvolvimento humano, deve-se estudar o meio para verificar as barreiras conceituais, atitudinais e procedimentais, incluindo os objetivos.

\section{PEI (Plano Educacional Individualizado)}

O PEI (Plano Educacional Individualizado) é um instrumento relativamente novo no Brasil, mas em outros países como Estados Unidos, Portugal, Catalunha, Áustria, Bélgica e Reino Unido já são muito utilizado na educação de crianças com alguma deficiência.

Um recurso para orquestrar, de forma mais efetiva, propostas 
pedagógicas que contemplem as demandas de cada aluno, a partir de objetivos gerais elaborados para a turma. É uma alternativa promissora, na medida em que oferece parâmetros mais claros a serem atingidos, sem negar os objetivos gerais colocados pelas propostas curriculares. (GLAT; PLETSCH, 2013, p. 22)

Considerando que $90 \%$ dos alunos TEAs não acompanham os conteúdos e atividades desenvolvidos em sala de aula (GOMES; MENDES, 2010), o PEI é muito importante para este público, pois é um planejamento individual que fornece um norte para que os professores de um ensino colaborativo (MENDES, 2006) trabalharem e desenvolverem os maiores potenciais da criança em questão, pois "diversificar os momentos e as estratégias de ensino-aprendizagem para o mesmo conteúdo e na mesma sala de aula, oportuna e adequadamente, é elemento essencial para atingir o sucesso na aprendizagem"(SANCHES, 1996, p.41)

Este instrumento é revisto de tempos em tempos por quem o definiu e prevê algumas metas para sua execução, como: investigar seus centros de interesse, histórico e passagem do aluno pela escola considerando o processo de aprendizagem e conhecendo-o para verificar suas verdadeiras necessidades. Este é o primeiro passo. Em seguida, é necessário estabelecer metas de curto, médio e longo prazo para depois elaborar um programa definindo o tempo de início e término para o que foi planejado com a devida avaliação.

Levando em conta que o professor já investigou os centros de interesse deste aluno, suas potencialidades e necessidades, neste plano deve conter os dados do aluno, da escola, dos profissionais envolvidos, o que este já sabe de conteúdo e o que ainda precisa adquirir, recursos, estratégias, expectativas, habilidades e procedimentos a ser utilizado.

Sobre os conteúdos que o aluno precisa adquirir, é importante averiguara função cognitiva, social e motora para perceber as reais necessidades no seu desenvolvimento funcional.

Quando falamos em função cognitiva podemos considerar alguns fatores como sugestão para um olhar diferenciado e preenchimento deste 
instrumento: atenção para selecionar ou manter o foco,tempos de concentração, compreensão de ordens faladas ou escritas e identificação e nomeação de tudo que o cerca; percepção visual, auditiva, tátil, cinestésica, espacial e temporal ; memória auditiva, visual, verbal e numérica; linguagem como expressão e compreensão da língua portuguesa, com o ritmo da fala,qualidade de como se expressa oralmente, da forma como se lê e intensidade da escrita; raciocínio lógico com conceitos matemáticos que são inseridos desde o ensino infantil como classificação, seriação,espaço, tempo, igualdades e diferenças, consequências, conclusões e causalidades do cotidiano; sequências lógicas; resolução de problemas e enunciados.

Ao descrever a função social, devemos mencionar o aspecto afetivo, emocional e social considerando a forma como se relaciona socialmente com estabelecimento e preferência de contatos horizontais ou verticais, estado emocional quanto à frustração, isolamento, cooperação, medo e relações com a afetividade. Terminando com a função motora no que diz respeito a postura adequada ao sentar e combinação de movimentos, lateralidade, equilíbrio, orientação espaço temporal, formas de locomoção e coordenação motora fina e global.

Estes aspectos devem estar baseados no desenvolvimento típico como parâmetro, $e$ se necessário solicitar ajuda de equipe multidisciplinar para avaliação, já que este olhar deve ser de um professor especializado com as demandas de um desenvolvimento global para este aluno.

Todos aprendem, porém cada um tem um tempo diferente e uma necessidade especifica, sendo necessárias muitas vezes algumas estratégias diferenciadas. Tendo em vista as funções cognitivas, podemos compreender o estilo de aprendizagem preferido que cada aluno elege para se desenvolver melhor.Na sua grande maioria, os TEAs se demonstram muito imagéticos e visuais, tendo o canal da visão um caminho mais rápido para aprender, por isso eles aprendem muito mais vendo do que ouvindo.

"Em vez de pressupor que o aluno deva ajustar-se a padrões de "normalidade" para aprender, aponta para a escola o desafio de ajustar-se para atender a diversidade de seus alunos" (BRASIL, 2001, p. 33). É isto 
que o PEI vai fazer, ajudar a concretizar este processo de ensinoaprendizagem.

O professor também pode solicitar ajuda dos profissionais da sala de recursos ou AEE pois esta também é uma das atribuições deste cargo, apoiar o trabalho do professor da sala regular.

\section{MÉTODO E RESULTADOS}

O desenvolvimento desta pesquisa foi realizado com duas amostras diferentes: uma com professores titulares de classe regular que lecionava para alunos TEAs e outra com professores apoio que são os professores auxiliares destinados a realizar um trabalho especifico com este aluno autista em sala regular apoiando o trabalho do professor titular. Participaram $60 \%$ de professores titulares de classe que tinham alunos do transtorno do espectro autista (TEA) sem apoio na sala e $80 \%$ de professores apoio que norteava a aprendizagem dos alunos com autismo no município de Jaguariúna no Ensino Fundamental I.Todas eram do sexo feminino entre 26 e 40 anos de idade com mais de 6 anos de efetivo exercício do magistério, e $90 \%$ de todos os professores envolvidos possuíam algum curso de pós graduação, sendo que apenas 30\% deste público possuía especialidade na área de educação especial ou inclusiva. Utilizamos observações, questionários semiestruturados e entrevistas com estes professores para o desenvolvimento desta pesquisa.

Nos questionários, perguntamos se os professores conheciam o que eram adequações curriculares, em que nível da sua formação docente tiveram acesso a esta ferramenta, se conheciam as peculiaridades do transtorno do espectro autista, que suporte teórico utilizavam para fazer as adequações e os que utilizavam, se viram progressos significativos na sua aprendizagem depois da implementação das adequações.

Os professores titulares que ficavam sozinho com seus alunos TEAs, não realizavam adequações curriculares e nem sabiam por onde 
começar a fazer essa tarefa, com exceção de uma professora que colocou o aluno perto da mesa da professora, longe da porta por conta dos barulhos, sem estímulos nas paredes, com rotina especifica e personalizada, ajustes nas atividades do material apostilado utilizado pois o aluno conseguia acompanhar o conteúdo da sala, legendas nos textos, figuras explicativas e tarefas mais curtas, sinalizadores, sendo por muitas vezes escriba deste aluno para produção textual.

A maioria dos professores auxiliares realizavam adequações curriculares de pequeno porte para os autistas, sem saber que este era o nome dado as atividades desenvolvidas por eles, porém poucos professores auxiliares tinham propriedade no que realizavam, mas conseguiam evidenciar o crescimento pedagógico deles. Apesar destes professores realizarem as adequações por intuição, não conseguiam entender alguns comportamentos expressos pelos seus alunos.

Os alunos mencionados durante a entrevista eram de grau leve ou moderado, com nível de linguagem verbal, porém com poucas funcionalidades na linguagem expressiva.

A grande maioria dos professores relatou como queixa que estes alunos possuíam bons vínculos com os profissionais educativos como algo positivo, porém como negativo, que eram crianças muito difíceis e que eles se utilizavam de choros, ou gritos quando não queriam fazer algo se confundindo com falta de limite. Muitas vezes não respondiam as questões que a professora sabia que ele tinha condições de fazer e faziam birras quando tinha que se expor dando a opinião ou fazendo uma escolha simples. Tudo isto nos leva a concluir que as características de hipersensibilidades dos autistas e a seletividade própria do espectro autista, devem ser mais difundidas para facilitar o trabalho do professor, caindo novamente no aspecto formação docente, pois tudo o que foi relatado pelos professores, fazem parte das características do próprio espectro. 


\section{CONCLUSÃO}

Em virtude dos dados apresentados, verificamos que esta pesquisa foi de extrema relevância para apontar que as adequações curriculares são eficazes para alunos com transtorno do espectro autista que apresentam dificuldades de se ajustar ao sistema educacional vigente, podendo apoderar-se do currículo para serie/ano matriculado.

A ação pedagógica necessita andar lado a lado com a teoria pois é ela que embasa a prática. Com a pesquisa, pudemos verificar que muitos profissionais ainda se apoiam na intuição para ajustar as práticas educativas inclusivas e muitos ainda necessitam de orientação para assim o promover pois não conhecem o caminho que devem trilhar e desconsideram as particularidades e potencialidades do alunado, colidindo por vezes com a verdadeira perspectiva da inclusão na sua totalidade.

A inclusão de alunos com TEA é muito delicada por conta de vários fatores e distratores que o próprio espectro acomete este alunado, como suas variadas hipersensibilidades e sua própria comunicação, necessitando de ajustes e adaptações no processo de ensino-aprendizagem, sendo as adequações curriculares uma poderosa ferramenta para promover o acesso ao currículo e permanência deste aluno na escola regular com um ensino estruturado de qualidade.

As adequações curriculares vão nortear uma escola inclusiva pois somos levados a acreditar que a teoria, conhecimento e prática pode ajudar a execução do trabalho pedagógico. Os dados apresentados sugerem que sejam realizadas boas formações docentes e inclusivas, para se atingir a aprendizagem, acesso e permanência destas crianças, em especial alunos TEAs. Essas diretrizes nos levam a acreditar que as escolas tenham mais sucesso com o processo inclusivo na escola regular com o uso das adequações curriculares de pequeno e grande porte respeitando as peculiaridades do alunado. 


\section{REFERÊNCIAS}

AINSCOW, Mel. Processo de inclusão é um processo de aprendizado. Entrevista: Mel Ainscow. São Paulo: CRE Mario Covas, 2016. Entrevista concedida a Secretaria de estado de Educação Especial. Disponível em: <http://www.crmariocovas.sp.gov.br/ees_a.php?t=002>. Acesso em:02 ago. 2016.

ASSMANN, Hugo. Metáforas novas para reencantar a

educação:epistemologia e didática. 3 ed. Piracicaba: Editora Unimep, 2001.

BLANCO, Rosa. A atenção à diversidade na sala de aula e as adaptações do currículo. In: COLL, César; MARQUES, Alvaro; PALÁCIOS, Jesús.

Desencolvimento psicológico e educaçao: transtornos de desenvolvimento e necessidades educativas especiais: Tradução de Fática Murad. Porto Alegre:ARTMED, 2004. Cap. 4. p.290-308. v. 3.

BRASIL. Lei no 9.394 de 20 de dezembro de 1996. Estabelece as diretrizes e bases da educação nacional. Diário Oficial da União, Brasília, 23 dez. 1996. Disponível em: < http://www.planalto.gov.br/ccivil_03/leis/L9394.htm >. Acesso em: 02 out. 2017.

BRASIL.Ministério da Educação.Diretrizes nacionais para a educação especial na educação básica.Brasília:MEC, 2001. Disponível em: <http://portal.mec.gov.br/seesp/arquivos/pdf/diretrizes.pdf>. Acesso em: 02 out. 2017.

BRASIL. Ministério da Educação. Projeto escola viva: garantindo o acesso e permanência de todos os alunos na escola: alunos com necessidades educacionais especiais: adaptações curriculares de grande porte. Brasília: MEC, 2000a. Disponível em:

<http://www.dominiopublico.gov.br/download/texto/me000448.pdf>. Acesso em: 02 out. 2017.

BRASIL. Ministério da Educação. Projeto escola viva:garantindo o acesso e permanência de todos os alunos na escola: alunos com necessidades especiais educacionais especiais: adaptações curriculares de pequeno porte. Brasília, MEC, 2000b. Disponível em:<http://www.dominiopublico.gov.br/download/texto/me000449.pdf >. Acesso em: 02 out. 2017.

BRASIL. Secretaria de Educação Fundamental. Parâmetros curriculares nacionais: adaptações curriculares. Brasília: MEC / SEF/SEESP, 1998.

CARVALHO, RositaEdler. Educação inclusiva: com os pingos nos "is". 4. 
ed. Porto Alegre: Ed. Meditação, 2006.

GLAT, Rosana; PLETSCH, Márcia Denise.Plano Educacional Individualizado (PEI): um diálogo entre práticas curriculares e processos de avaliação escolar. In: GLAT, Rosana; PLETSCH, Márcia Denise. (Org.). Estratégias educacionais diferenciadas para alunos com necessidades especiais. Rio de Janeiro/RJ: EDUERJ, 2013. v. 1, p. 17-32.

GLAT, R. (org.). Educação Inclusiva: cultura e cotidiano escolar. Rio de Janeiro: 7Lettras, 2009. p. 15-35.

GOMES, C.; MENDES, E. Escolarização inclusiva de alunos com autismo na rede municipal de ensino de Belo Horizonte. Revista Brasileira de Educação Especial, Marília, v. 16, n. 3, p. 375-396, 2010

GONZALEZ, José Antonio Torres. Educação e diversidade-bases didáticas e organizativas. Porto Alegre:ARTMED, 2002.

MASCARO, C. A. A. C. Capacitação de pessoas com deficiência intelectual para o trabalho: estudo de caso de um curso de Educação Profissional. Dissertação (Mestrado em Educação). Programa de PósGraduação em Educação, Universidade do Estado do Rio de Janeiro (UERJ), 2012.

MCLAREN, Peter. Multiculturalismo crítico. Rio de Janeiro: Cortez Editora, 1998.

MENDES, E. G. A radicalização do debate sobre inclusão escolar no Brasil. Revista Brasileira de Educação, Rio de Janeiro, v. 11, n. 33, p. 387-405, 2006.

OLIVEIRA, Ana Augusta Sampaio. Adequações curriculares na área da deficiência intelectual: algumas reflexões.In: OLIVEIRA, Ana Augusta Sampaio; OMOTE, Sadão; GIROTO, Claudia Regina Mosca (Org.) Inclusão escolar: as contribuições da educação especial.Sao Paulo: Cultura AcademicaMarilia:FUNDEPE, 2008.

PLETSCH, M.D; GLAT, R. Plano Educacional Individualizado (PEI): um diálogo entre as práticas curriculares e processos de avaliação escolar. In: GLAT, R; PLESTCH, M.D. (Orgs). Estratégias Educacionais Diferenciadas para alunos com necessidades especiais. pp. 17-32. Rio de Janeiro: EdUERJ, 2013.

PLETSCH, M. D. Repensando a inclusão escolar de pessoas com deficiência mental: diretrizes políticas, currículo e práticas pedagógicas. Tese de Doutorado. Programa de Pós-Graduação em Educação, Universidade do Estado do Rio de Janeiro (UERJ), 2009. 
PRIETO, Rosângela Gavioli. Trajetórias da política nacional de educação especial: focalizando o plano de desenvolvimento da educação PDE. In: MARQUEZINE, Maria Cristina et al. (Org.). Políticas públicas e formação de recursos humanos em educação especial. Londrina: ABPEE, 2009, p. 35-58.

REGANHAN, Walquíria Gonçalves; MANZINI, Eduardo José. Percepção de professores do ensino regular sobre recursos e estratégias para o ensino de alunos com deficiência. Revista Educação Especial, Santa Maria, v.22, n.34, p. 127-138, maio/ago.2009. Disponível em:

https://periodicos.ufsm.br/educacaoespecial/article/view/266/127>. Acesso em: 13 jul. 2015.

RESENDE, Lúcia Maria Gonçalves de; FORTES, Rodolfo Medeiros Cunha. Mudanças e inovações pedagógicas ma formação continuada de docentes.In: REUNIÃO ANUAL DA ANPED, 28., 2005, Caxambu. Mudanças e inovações. Caxambu: ANPED, 2005. p.01-16. v.1.

RODRIGUES, David. Educação Inclusiva: as boas e as más notícias. in: Rodrigues, David. (Org.) Perspectivas sobre a Inclusão; da Educação à Sociedade. Porto Editora, Porto. 2003.

SARRUBBI, E. Ristampaanastaticadell'edizione: Lugduni, P. Landry, 1610. Torino: Bottega d'Erasmo, 1971.

SAMPIERI, R. H.; COLLADO, C. F. e LUCIO, P. B. Metodologia de Pesquisa. 3 ed. São Paulo: McGraw Hill, 2006.

SANCHES, Isabel; TEODORO, António. Da integração à inclusao escolar: cruzando perspectivas e conceitos. Revista Lusófona de Educação, n. 08, 2006.

SEVERINO, Antônio Joaquim. Metodologia do Trabalho Científico. São Paulo: Cortez, 2007.

VASCONCELLOS, Celso dos Santos. Avaliação: concepção dialéticalibertadora do processo de avaliação escolar. 3. ed. São Paulo: Libertad, 1995.

VYGOTSKY, L. S. Obras escogidas: fundamentos de ladefectologia, Madrid: Visor, 1997.

WERNECK, C. Acorda mostro! Escritos da criança. n.5, p. 107-112, 1998. 